\title{
Enteroparasitoses in Patients with Rheumatoid Arthritis
}

\author{
Ana Paula Monteiro Gomides ${ }^{1 *}$, Alex Luiz de Oliveira Pires ${ }^{1}$, Cleandro Pires Albuquerque ${ }^{1}$, \\ Talita Yokoy de Souza1, Luciana Muniz'1, Caliandra Maria Bezerra Luna Lima², \\ Leopoldo Luiz Santos-Neto', Licia Maria Henrique da Mota ${ }^{1}$
}

\author{
${ }^{1}$ Universidade de Brasília (UnB), Brasília, Brazil \\ ${ }^{2}$ Universidade Federal da Paraíba, João Pessoa, Brazil \\ Email: *anapmgomides@gmail.com
}

How to cite this paper: Gomides, A.P.M., de Oliveira Pires, A.L., Albuquerque, C.P., de Souza, T.Y., Muniz, L., Lima, C.M.B.L., Santos-Neto, L.L. and da Mota, L.M.H. (2017) Enteroparasitoses in Patients with Rheumatoid Arthritis. Advances in Infectious Diseases, 7, 143-152.

https://doi.org/10.4236/aid.2017.74015

Received: October 11, 2017

Accepted: November 28, 2017

Published: December 1, 2017

Copyright $\odot 2017$ by authors and Scientific Research Publishing Inc. This work is licensed under the Creative Commons Attribution International License (CC BY 4.0).

http://creativecommons.org/licenses/by/4.0/

(c) (i) Open Access

\begin{abstract}
Background: Patients with rheumatic diseases have profound alterations in the immune system as a result of underlying diseases and the treatments used, which increases the risk of occurrence and severity of infections, including enteroparasitosis. The current treatment for rheumatoid arthritis involves immunosuppressive therapies powerfully needed for screening infectious processes. The prevalence of parasitic infections in rheumatoid arthritis patients is not currently documented in literature. The objective of the current study was to determine the prevalence of parasitic diseases in a population with RA. Methods: We collected demographic and socioeconomic data from 67 patients at the Hospital Universitário de Brasília from July 2015 to April 2016. All patients underwent a parasitological examination of their stool and multiple variables were analyzed using Poisson regression method. Results: The mean age of patients was 53.9 years. They were predominantly in women (94\%) and caucasian (47.8\%). The mean disease duration was 9.2 years and most patients had the disease in remission or light activity. The prevalence of parasitic infections in these patients was $11.9 \%$, all cases being that of protozoa of the following species: Endolimax nana, Entamoeba histolytica and Entamoeba coli. The final multivariate analysis indicated that the presence of disease had a significant statistical relationship between the presence of enteroparasitosis and rheumatoid arthritis with no fatigue by VAS ( $\mathrm{p}=0.0488)$ and best current health index by VAS $(\mathrm{p}=0.0012)$. Conclusion: This study indicates that the prevalence of enteroparasitoses in a population with Rheumatoid Arthritis was $11.9 \%$ and all cases were found of protozoa.
\end{abstract}

\section{Keywords}

Parasitic Infections, Rheumatoid Arthritis, Protozoosis, Enteroparasitoses, 
Intestinal Infection

\section{Introduction}

Intestinal parasitic infections are a public health problem in underdeveloped countries, but there are few studies examining actual patients, particularly in the area of rheumatology [1]. With availability of immunosuppressive treatments for rheumatoid arthritis (RA) progressively increasing, the risk of opportunistic infections by enteroparasites is also increasing [2] [3]. We also know that in addition to the risk of new infections, the possibility of reactivation of latent cases is also higher, which increases the chances of disease complications [4]. There has been a growing interest in researching the hypothesis that helminth may be involved in evolution of RA, although a great deal of further studies on this matter is necessary to evaluate the hypothesis in further detail [5]-[11]. The objective of the current study was to determine the prevalence of parasitic diseases in a population with RA, particularly focusing on the demographic of patients presenting with RA and parasitic infections. The information may facilitate screening and management of rheumatic patients in areas endemic to worm infestation.

\section{Methods}

We evaluated 67 patients previously diagnosed with RA and being treated at the University Hospital of Brasília UNB, Brazil. All selected patients met the criteria of EULAR/ACR 2010 [12] and signed the free and informed consent (WIC). During the study, patients were undergoing the standard treatment protocol recommended by the Consensus of the Brazilian Society of Rheumatology, including Medicine Modifiers of Course of the Disease (MMCDs), traditional and/or modifier therapy of biological response, in accordance with the case [13]. Patients were presented with questionnaires designed to obtain information relating to their personal identification, socioeconomic status, as well as lifestyle and living conditions. Patients' economic status was defined according to the Economic Classification Criterion of Brazil (ECCB), which estimates the purchasing power of urban families [14]. Subsequently, a rheumatologic evaluation was carried out on all patients in the cohort, gathering information regarding the history of their disease, visual analog scales and HAQ. Participants also underwent a complete physical examination, including count of tender and swollen joints. The following composite indices of disease activity were calculated (ICAD's): Disease activity score-28 joints (DAS28), clinical disease activity index (CDAI) and simplified disease activity index (IFDS) [15].

In addition, participants underwent laboratory tests (ESR and CRP), a stool test (EPF), occult blood in the stool and fecal fat. Fecal material was analyzed via the sedimentation method and concentration, performing three readings in each preparation [16]. In addition to basic techniques of exploratory analysis as de- 
termination of frequencies and median, bivariate analysis was performed alongside Poisson regression analysis with robust variance. All statistical analysis in this work considered statistical significance to be $\mathrm{p}<0.05$. This study was approved by the Research Ethics Committee of the medical school of the University of Brasilia.

\section{Results}

Of the 67 RA patients analyzed in this study were analyzed with rheumatoid arthritis frame, 63 (94\%) were female with a mean age of 53.9 years (standard deviation (SD) of 12.3 years). All participants were from urban areas and claimed to have running water at home. Other Further demographic data from this cohort member of this population are summarized in Table 1 . When analyzing their habits, 14 patients (20.9\%) had a history of previous smoking and 4 (6.25\%) reported currently smoking; 44 (65.7\%) subjects performed regular physical activity by 2 or more times per week and the classification of their body weight, measured by BMI, found that 30 evaluated had a normal index (44.8\%), 21 were overweight (31.3\%) and 16 showed varying degrees of obesity (23.8\%).

Regarding RA characteristics, we found that 54 patients (80.6\%) of the sample were seropositive compared to the rheumatoid factor, and 39 (58.2\%) had high titers (greater amount than 3 times or more than the upper limit of normality). Nine individuals (13.4\%) had erosive disease and three 3 had extra articular manifestations ( 2 with subcutaneous nodules and 1 with pulmonary manifestations). The mean duration of disease in the sample was 9.1 years. The analysis of composite indices of disease activity (ICAD's), HAQ and visual analog scales can be seen in Figure 1, Figure 2 and Table 2 respectively.

As for the result of the parasitological examination indicated that protozoa were present in, changes were observed in $8(11.9 \%)$ of the patients. The

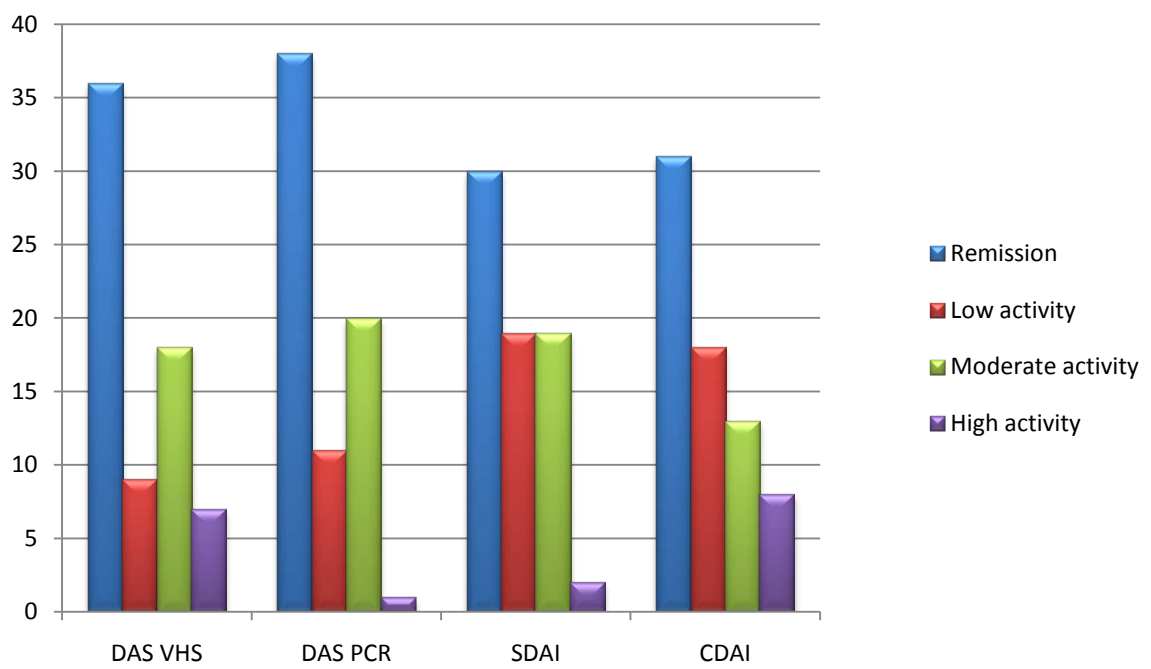

Figure 1. Composite indices of disease activity calculated in the sample of 67 patients with RA. 
Table 1. Socio-demographic characteristics of 67 patients with rheumatoid arthritis: absolute and relative frequency of each variable sample.

\begin{tabular}{|c|c|c|c|}
\hline \multirow{2}{*}{$\begin{array}{c}\text { Variable category } \\
\text { Gender }\end{array}$} & \multirow{2}{*}{$\begin{array}{c}\mathrm{n} \\
\text { Female }\end{array}$} & \multicolumn{2}{|c|}{$\%$} \\
\hline & & 63 & 94 \\
\hline & Male & 4 & 6 \\
\hline \multirow[t]{4}{*}{ Ethnic group } & White & 32 & 47.8 \\
\hline & Mestizo & 29 & 43.3 \\
\hline & Black & 5 & 7.5 \\
\hline & Indigenous & 1 & 1.4 \\
\hline \multirow[t]{4}{*}{ Civil status } & Single & 23 & 34.3 \\
\hline & Married & 32 & 47.8 \\
\hline & Divorced & 7 & 10.4 \\
\hline & Widower & 5 & 7.5 \\
\hline \multirow[t]{8}{*}{ Educates status } & Illiterate & 6 & 8.9 \\
\hline & Incomplete first grade & 17 & 25.4 \\
\hline & Complete first grade & 13 & 19.4 \\
\hline & Incomplete second grade & 2 & 3 \\
\hline & Complete second grade & 19 & 28.3 \\
\hline & Incomplete college & 2 & 3 \\
\hline & Complete college & 5 & 7.5 \\
\hline & Postgraduate & 3 & 4.5 \\
\hline \multirow[t]{5}{*}{ Social class } & $\mathrm{B} 1$ & 3 & 4.5 \\
\hline & B2 & 14 & 20.9 \\
\hline & $\mathrm{C} 1$ & 23 & 34.3 \\
\hline & $\mathrm{C} 2$ & 17 & 25.4 \\
\hline & $\mathrm{D}-\mathrm{E}$ & 10 & 14.9 \\
\hline \multirow[t]{4}{*}{ Age } & Average & & 53.9 \\
\hline & Stand art deviation & & 12.3 \\
\hline & Minimum & & 26 \\
\hline & Maximum & & 80 \\
\hline \multirow[t]{4}{*}{ Years of study } & Average & & 8.3 \\
\hline & Stand art deviation & & 4.6 \\
\hline & Minimum & & 0 \\
\hline & Maximum & & 16 \\
\hline
\end{tabular}

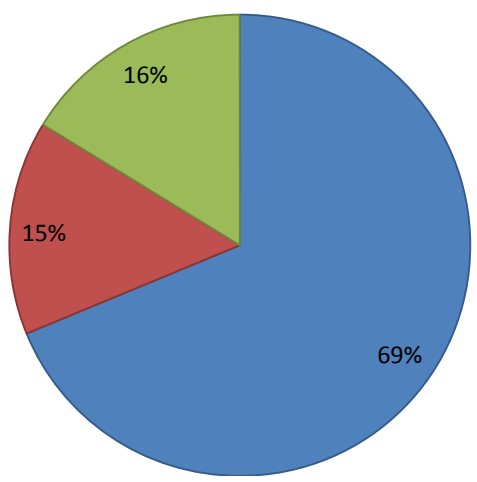

Mild disability (HAQ=0-1)

$\square$ Moderate disability (HAQ > 1- 2)

$\square$ Severe disability (HAQ $>2-3$ )

Figure 2. Disability evaluation by HAQ of 67 patients with rheumatoid arthritis. 
Table 2. Visual analogue scale (value: 0 - 100) of patients with rheumatoid arthritis.

\begin{tabular}{ccc}
\hline Visual analogue scale & Média & Desvio Padrão \\
\hline Pain & 16.09 & 22.602 \\
Fatigue & 20.72 & 27.936 \\
Disease activity & 16.56 & 19.279 \\
General health today & 17.19 & 19.549 \\
\hline
\end{tabular}

presence of protozoa was seen in all of them. The distribution of type of protozoa type was as follows: 5 patients (7.4\%) showed Endolimax nana cysts, 2 (3\%) had cysts Entamoeba histolytica/Entamoeba dispar and 1 patient (1.4\%) had Entamoeba coli. There was no positive observation of helminths in this sample. Additionally, 3 patients tested positive for fecal occult blood and fecal fat was observed in 5 patients without concomitant parasites in these cases.

When we look at the socio-demographic and clinical characteristics of patients with protozoa, we found a statistically significant relationship with the absence of fatigue by VAS $(\mathrm{p}=0.048)$ and best current health status by VAS $(\mathrm{p}=$ 0.001). There was a positive correlation of changes in EPF with the other variables.

Cases positive for fecal fat and fecal occult blood did not correlate with any specific condition.

\section{Discussion}

The socio-demographic characteristics of the current sample (RA, early age, gender, etc.) were are similar to those found in other studies of RA within the Brazilian population [17]. In our study, In relation to data on the disease, we observed that most of the samples cases were rheumatoid factor seropositive, female women compared to rheumatoid fator and the disease was in remission.

In our study, analysis of the stool indicated. When the stool test was analyzed, $11.9 \%$ of patients tested positive for protozoa. This prevalence is similar to another recent study in Brazil, in which the occurrence of protozoa was $15.1 \%$ [18].

Several of the protozoan subtypes found in our patients, Endolimax nana and Entamoeba coli, revealed that Endolimax nana and Entamoeba coli are considered human intestinal commensal and therefore nonpathogenic. In spite of despite this fact that it does not cause diseases, it is important to mention that presence of these microbes it is usually borne as the result of poor quality of water and/or food quality, food and/or as well as fecal contamination. In our study, all patients were residents of the urban areas with pipe borne water, but were low income earners and possibly with inadequate sanitary conditions. This finding may suggest the need for greater attention on to water treatment, food handling and hygiene guidelines for rheumatic patients, especially those using immunosuppressants. 
Entamoeba histolytica, on the other hand, is the cause of amebiasis, and is disease transmitted through contaminated food/and water. This protozoa has a mortality rate only second to malaria and the second protozoan of higher mortality after malaria [19]. There are many asymptomatic cases that may manifest as diarrheal syndrome, intestinal ulceration and even liver abscess, the latter being considered a serious extra-intestinal complication [19] [20]. In our study we found 2 positive cases of Entamoeba histolytical dispar, morphologically identical species and therefore no possibility of differentiating with the methodology used [21].

Individuals who participated in this study, did not have mal-absorption syndrome symptoms, yet the presence of fecal fat was found in 5 cases $(7.1 \%)$ of the sample. We did not find in the literature does not report other fecal fat elimination to occur of reports in patients with RA and this possible association should be further investigated further. Another finding of this study was the presence of occult blood in 3 patients (4.2\%). This fact deserves attention from of rheumatologists when in the management of patients with RA, given the possibility of bleeding from the gastrointestinal tract as result of, secondary to the use of drugs treatments or other concomitant diseases.

Two other associations found in this study are noteworthy. There was a statistically significant relationship between lack of absence of fatigue and better overall current state of health, the according to the visual analogue scale, with positive in cases positive for of protozoa.

The complaint of fatigue in patients with RA is extremely common and its causes have been much researched. Systemic manifestations, sleep disorders, sedentary lifestyle and psychosocial factors have been reported to be aggravating [22] [23].

The relationship between best parameters of VAS fatigue and VAS current health status with protozoan infections has been not found in other studies in the literature. In rheumatoid arthritis, there is no current yet work looking at prevalence of parasites and therefore, we have no data comparison parameters for found in this population. A possible protective role of protozoa in patients with RA may be suspected, which would explain the findings of this study, but has not been reported in the literature. On the other hand, a protective effect of helminths in RA has been investigated in several studies and confirmed by several authors [5] [6] [7] [8] [24]-[33].

The work carried out had some limitations. The sample selected was a small number of respondents, coming from a tertiary hospital and with cross-sectional evaluation. These factors allow you to consider the results only for the population studied. It did not allow extrapolation and measurement of cause and effect. The absence of specific techniques in the completion of the EPF was another limiting factor. However spontaneous sedimentation has been widely used in scientific work due to its low cost and ease of application. Furthermore, the visual analog scales are one-dimensional and subjective measures. 
Despite the limitations the above, this is the first study on the prevalence of parasitic infections in RA to date and the data found may support future research in this area.

\section{Conclusions}

The present study found a prevalence of $11.9 \%$ of parasitic infections in patients with rheumatoid arthritis. All cases were found of were protozoa with the following species distribution by species: 5 patients (7.4\%) had cysts of Endolimax nana, 2 (3\%) had cysts of Entamoeba histolytica and 1 patient (1.5\%) with Entamoeba coli. There were no cases of helminthiasis.

There was no relation between of positive cases of parasitic diseases with specific social class.

In addition, the association of cases of protozoan infections were associated with a lower level of fatigue was observed with lower levels of fatigue and better current health status as established by the visual analog scale.

\section{Financial Disclosure}

The authors have no financial relationships relevant to this article to disclose.

\section{Conflict of Interest}

The authors have no conflicts of interest to disclose.

\section{Acknowledgements}

Thanks to the Laboratory Sabin-DF for financing and carrying out the tests used in this study.

Also to the Rheumatology Team at the University Hospital of Brasilia for their support during the entire study.

\section{References}

[1] Andrade, E.C., Leite, I.C.G., Rodrigues, V.O. and Cesca, M.G. (2010) Intestinal Parasitic Diseases: A Review of Social, Epidemiologic, Clinical and Therapeutic Aspects. Rev APS Juiz de Fora, 13, 231-240.

[2] Fabiani, S. and Bruschi, F. (2014) Rheumatological Patients Undergoing Immunosuppressive Treatments and Parasitic Diseases: A Review of the Literature Cases of Clinical Perspectives and to Screen and Follow-Up Active and Latent Chronic Infections. Clinical and Experimental Rheumatology, 32, 587-596.

[3] Bartalesi, F., Bartoloni, A., Bisoffi, Z., Spinicci, M., Giménez Sánchez, F. and Muñoz, J. (2014) The Emerging Problem of Biological Treatment in Migrant and Traveling Populations: It Is Time to Extend Guidelines for the Screening of Infectious Diseases. Annals of the Rheumatic Diseases, 73, 794-796. https://doi.org/10.1136/annrheumdis-2013-203848

[4] Tektonidou, M.G. and Skopouli, F.N. (2008) Visceral Leishmaniasis in a Patient with Psoriatic Arthritis Treated with Infliximab: Reactivation of a Latent Infection? Clinical Rheumatology, 27, 541-542. https://doi.org/10.1007/s10067-007-0775-y

[5] Rzepecka, J., Pineda, M.A., Al-Riyami, L., Rodgers, D.T., Huggan, J.K. and Lumb, 
F.E. (2015) Prophylactic and Therapeutic Treatment with a Synthetic Analogue of the Parasitic Worm Product Arthritis and Inhibits IL-1 $\beta$ Experimental Prevents Production via NRF2-Mediated Counter-Regulation of the Inflammasome. Journal of Autoimmunity, 60, 59-73. https://doi.org/10.1016/j.jaut.2015.04.005

[6] Aprahamian, T.R., Zhong, X. and Amir, S. (2015) The Immunomodulatory Product Parasitic Worm ES-62 Lupus-Associated Angiograms Accelerated Atherosclerosis in a Mouse Model. International Journal for Parasitology, 45, 203-207. https://doi.org/10.1016/j.ijpara.2014.12.006

[7] Al-Riyami, L., Rodgers, D.T., Rzepecka, J., Pineda, M.A., Suckling, C.J. and Harnett, M.M. (2015) Protective Effect of Small Molecule Analogues of the Acanthocheilonema viteae Secreted Product ES-62 on Oxazolone-Induced Ear Inflammation. Experimental Parasitology, 158, 18-22. https://doi.org/10.1016/j.exppara.2015.03.025

[8] Pineda, M., Al-Riyami, L. and Harnett, W. (2014) Lessons from Helminth Infections: ES-62 Highlights New Interventional Approaches in Rheumatoid Arthritis. Clinical and Experimental Immunology, 177, 13-23. https://doi.org/10.1111/cei.12252

[9] McInnes, I.B., Leung, B.P., Harnett, M., Gracie, J.A., Liew, F.Y. and Harnett, W. (2003) A Novel Therapeutic Approach Targeting Articular Inflammation Using the Filarial Nematode-Derived Phosphorylcholine-Containing Glycoprotein ES-62. The Journal of Immunology, 171, 2127-2133. https://doi.org/10.4049/jimmunol.171.4.2127

[10] da Rocha, F.A.C. (2006) Protective Role of Helminthiasis in the Development of Autoimmune Diseases. Clinical and Developmental Immunology, 13, 159-162. https://doi.org/10.1080/17402520600876895

[11] Rocha, F.A.C., Leite, A.K.R.M., Pompeu, M.M.L., Cunha, T.M., Verri Jr., W.A. and Soares, F.M. Protective Effect of An Extract from Ascaris suum in Experimental Arthritis Models. Infection and Immunity, 76, 2736-2745. https://doi.org/10.1128/IAI.01085-07

[12] Arnett, F.C., Edworthy, S.M., Bloch, D.A., McShane, D.J., Fries, J.F. and Cooper, N,S. (1998) The American Rheumatism Association 1987 Revised Criteria for the Classification of Rheumatoid Arthritis. Arthritis \& Rheumatology, 31, 315-324. https://doi.org/10.1002/art.1780310302

[13] Da Mota, L.M.H., Cruz, B.A., Albuquerque, C.P., Gonçalves, D.P., Laurindo, I.M.M. and Pereira, I.A. (2016) Update on the 2012 Brazilian Society of Rheumatology Guidelines for the Treatment of Rheumatoid Arthritis: Position on the Use of Tofacitinib. Revista Brasileira de Reumatologia, 55, 512-521.

https://doi.org/10.1016/j.rbr.2015.08.004

[14] Martins, R.J., Garcia, A.R., Garbin, C.A.S. and Sundefeld, L.M.M. (2008) The Relation between Socio-Economic Class and Demographic Factors in the Occurrence of Temporomandibular Joint Dysfunction. Science \& Public Health, 13, 2089-2096.

[15] Aletaha, D.S.J. (2003) The Simplified Disease Activity Index (IFDS) and the Clinical Disease Activity Index (CDAI): A Review of Their Usefulness and Validity in Rheumatoid Arthritis. Clinical and Experimental Rheumatology, 23, 100-108.

[16] Ribeiro, S.R. and Furst, C. (2012) Parasitological Stool Sample Exam by Spontaneous Sedimentation Method Using Conical Tubes: Effectiveness, Driving Range, and Biosafety. Revista da Sociedade Brasileira de Medicina Tropical, 45, 399-401. https://doi.org/10.1590/S0037-86822012000300024 
[17] da Mota, L.M., Laurindo, I.M. and dos Santos Neto, L.L. (2010) Demographic and Clinical Characteristics of a Cohort of Patients with Early Rheumatoid Arthritis. Revista Brasileira de Reumatologia, 50, 235-248.

[18] Casavechia, M.T., Lonardoni, M.V., Venazzi, E.A., Campanerut-Sá, P.A, da Costa Benalia, H.R. and Mattiello, M.F. (2016) Prevalence and Predictors Associated with Intestinal Infections by Protozoa and Helminths in Southern Brazil. Parasitology Research, 115, 2321-2329. https://doi.org/10.1007/s00436-016-4980-y

[19] Walsh, J.A. (1986) Problems in Recognition and Diagnosis of Amebiasis: Estimation of the Global Magnitude of Morbidity and Mortality. Reviews of Infectious Diseases, 8, 228-238. https://doi.org/10.1093/clinids/8.2.228

[20] Vilajeliu Balagué, A., de las Heras Prat, P., Ortiz-Barreda, G., Pinazo Delgado, M.J., Gascón Brustenga, J. and Bardají Alonso, A. (2014) Imported Parasitic Diseases in the Immigrant Population in Spain. Revista Española de Salud Pública, 88, 783-802. https://doi.org/10.4321/S1135-57272014000600010

[21] Santos, F.L.N. and Soares, N.M. (2008) Pathophysiological Mechanisms and Laboratory Diagnosis of Infection Caused by Entamoeba histolytica. Brazilian Journal of Pathology and Laboratory Medicine, 44, 249-261. https://doi.org/10.1590/S1676-24442008000400004

[22] Mayoux-Benhamou, M.A. (2006) Fatigue and Rheumatoid Arthritis. Annales De Readaptation Et De Medecine Physique, 49, 301-304. https://doi.org/10.1016/j.annrmp.2006.04.012

[23] Katz, P., Margaretten, M., Trupin, L., Schmajuk, G., Yazdany, J. and Yelin, E. (2016) Role of Sleep Disturbance, Depression, Obesity, and Physical Inactivity in Fatigue in Rheumatoid Arthritis. Arthritis Care \& Research, 68, 81-90. https://doi.org/10.1002/acr.22577

[24] Rodgers, D.T., McGrath, M.A., Pineda, M.A., Al Riyami, L., Rzepecka, J. and Lumb, F. (2015) The Parasitic Worm Product ES-62 Targets Myeloid Differentiation Factor 88-Dependent Effector Mechanisms to Suppress Antinuclear Antibody Production and Proteinuria in MRL/lpr Mice. Arthritis \& Rheumatology, 67, 1023-1035. https://doi.org/10.1002/art.39004

[25] Egan, C.A., Houston, K.M., Alcocer, M.J.C., Solovyova, A., Tate, R. and Lochnit, G. (2006) Lack of Immunological Cross-Reactivity between Parasite-Derived and Recombinant Forms of ES-62, the Secreted Protein of Acanthocheilonema viteae. Parasitology, 132, 263-274. https://doi.org/10.1017/S0031182005009005

[26] Greenwood, B.M. and Herrick, I.N. (1970) Can Parasitic Infection Suppress Autoimmune Disease? Proceedings of the Royal Society of Medicine, 63, 18-20.

[27] Osada, Y., Shimizu, S., Kumagai, T. and Yamada, S.K.T. (2009) Schistosoma Mansoni Infection Angiograms Severity of Collagen-Induced Arthritis via Down-Regulation of Pro-Inflammatory Mediators. International Journal for Parasitology, 39, 457-464. https://doi.org/10.1016/j.ijpara.2008.08.007

[28] Itami, D.M., Oshiro, T.M., Araujo, C.A., Perini, A., Martins, M.A. and Macedo, M.S. (2005) Modulation of Murine Experimental Asthma by Ascaris suum Components. Clinical \& Experimental Allergy, 35, 873-879. https://doi.org/10.1111/j.1365-2222.2005.02268.x

[29] Nagayama, Y., Watanabe, K., Niwa, M., McLachlan, S.M. and Rapoport, B. (2004) Schistosoma Mansoni and Alpha-Galactosylceramide: Prophylactic Effect of Th1 Immune Suppression in a Mouse Model of Graves' Hyperthyroidism. The Journal of Immunology, 173, 2167-2173. https://doi.org/10.4049/jimmunol.173.3.2167

[30] La Flamme, A.C., Ruddenklau, K. and Bäckström, B.T. (2003) Schistosomiasis 
Central Nervous System Decreases Inflammation and Alters the Progression of Experimental Autoimmune Encephalomyelitis. Infection and Immunity, 71, 4996-5004. https://doi.org/10.1128/IAI.71.9.4996-5004.2003

[31] Mattsson, L., Larsson, E., Erlandsson-Harris, M., Klareskog, L. and Harris, R.A. (2000) Parasite-Mediated Down-Regulation of Collagen-Induced Arthritis (CIA) in DA Rats. Clinical \& Experimental Immunology, 122, 477-483. https://doi.org/10.1046/j.1365-2249.2000.01384.x

[32] Cooke, A., Tonks, P., Jones, F.M., O'Shea, H., Hutchings, P., Fulford, A.J. and Dunne, D.W. (1999) Infection with Schistosoma Mansoni Prevents Insulin Dependent Diabetes Mellitus in Non-Obese Diabetic Mice. Parasite Immunology, 21, 169-176. https://doi.org/10.1046/j.1365-3024.1999.00213.x

[33] Oliveira, S.M., Gomides, A.P., Mota, L.M., Lima, C.M. and Rock, F.A. (2016) Intestinal Parasites Infection: Protective Effect in Rheumatoid Arthritis? Revista Brasileira de Reumatologia, 30035-3. https://doi.org/10.1016/j.rbr.2016.04.002 